\title{
Changes in L1 Antigen Expression in the Rat Striatum after Substantia Nigra Lesions
}

\author{
Maciej Poltorak, Jamesine R. Williams, Kraig D. Moore, and Willam J. Freed \\ Section on Preclinical Neuroscience, Neuropsychiatry Branch, \\ NIMH Neuroscience Center at St. Elizabeths, Washington, D.C. 20032, U.S.A.
}

\section{SUMMARY}

L1 antigen promotes neurite outgrowth from dopaminergic neurons in tissue culture. In the present study, we examined the effects of dopaminergic deafferentation of the striatum on L1 expression. In the medial-periventricular part of the striatum, both complete and partial substantia nigra (SN) lesions decreased L1 expression. Complete lesions increased $\mathrm{L1}$ expression in the dorso-medial and ventrolateral parts of the striatum on the lesioned side when compared with that on the non-lesioned side. The decrease in the ventro-lateral area was maintained in animals examined three months after the lesioning. Animals with partial SN lesions showed a different pattern of altered $\mathrm{L} 1$ expression. After frontal cortex lesions, changes dorso-medial and periventricular striatum. Therefore, the results indicate a complex regulation of $L 1$ expression after damage of striatal circuitry, manifested by a preferential occurrence of changes in periventricular regions.

\section{KEY WORDS}

cell-recognition molecule, CRM, cell-adhesion molecule, regeneration, deafferentation in $\mathrm{L} 1$ expression also occur preferentially in the

\section{INTRODUCTION}

The L1 antigen belongs to the family of cellrecognition molecules (CRMs) that play important roles in development, plasticity, and regeneration of the nervous system $/ 13,14 /$. The L1 antigen is involved in neuronal-process outgrowth $/ 5,12,17 /$ and in neural migration on glial-cell fibers. During formation of the mesencephalic-striatal pathway, L1 antigen expression is enhanced on growing axons, and the antigen is thought to be involved in axonal elongation from substantia nigra (SN) dopaminergic neurons $/ 16 /$. L1 antigen also promotes neurite outgrowth from cultured dopaminergic neurons $19,10 /$. Indeed, expression of $\mathrm{L} 1$ antigen in the brain can be regulated not only by intrinsic signals but also, to some extent, by extrinsic signals. In rodents, for example, removal of cortico-striatal afferents induces an increase in $\mathrm{L} 1$ antigen expression within the medial-periventricular region but not in other areas of the striatum $/ 11 /$. The anatomical distribution of changes does not correlate well with the regions of striatal deafferentation after cortex ablation $/ 11 /$. The data suggest that a lesion in one brain area can induce disturbances in $\mathrm{Ll}$ antigen synthesis in other areas. In addition to glutamatergic afferentation, the striatum also receives a major input from dopaminergic neurons in the SN. The present study was undertaken to investigate whether changes in L1-antigen expression occur after dopaminergic deafferentation of the striatum.

\section{METHODS}

Reprint address:

Maciej Poltorak

NIMH Center at St. Elizabeths

Washington DC 20032, USA

Fax 202-373-6248; Tel: 202-373-6148
Sprague-Dawley rats $(n=34)$ weighing $200-230$ g each, were maintained according to the NIH Guide for the Care and Use of Laboratory Animals. The rats received SN lesions as previously 
described /1/. Briefly, rats anesthetized with ketamine $(70 \mathrm{mg} / \mathrm{kg})$ and Rompun $(6 \mathrm{mg} / \mathrm{kg})$, given intramuscularly (i.m.), were mounted in a stereotaxic instrument. 6-Hydroxydopamine hydrobromide ( $8 \mathrm{mg}$ free base in $4 \mathrm{ml}$ saline containing $0.05 \%$ ascorbic acid) (Sigma Chemical Co.) was infused unilaterally into the right SN. Seven days later, the rats were tested for rotational behavior after receiving a subcutaneous (s.c.) injection of apomorphine hydrochloride $(0.1 \mathrm{mg} / \mathrm{kg})$. Complete $360^{\circ}$ rotations in flat-bottomed, cylindrical jars were measured using automated rotometer devices. Rats $(n=22)$ showing more than 100 turns/h contralateral to the lesions after apomorphine treatment (rotators) were considered to have complete SN lesions. The rotators were divided into two groups: The rats in Group 1 were sacrificed 10 days later (short-term, $\mathrm{n}=7$ ); rats in Group 2 were sacrificed 3 months later (long-term, $\mathrm{n}=15$ ). Rats considered to have incomplete SN lesions (non-rotators, $\mathrm{n}=12$ ), were sacrificed 10 days later (short-term nonrotators).

Brains of decapitated rats were quickly removed, frozen, and sectioned. The location of SN lesions was verified by examining cresyl-violet-stained sections (data not shown). Immunostaining was performed essentially according to Schachner $/ 13 /$. Different groups of matching frontal sections of anterior striatum from all animals were simultaneously labeled in one batch using a polyclonal antiserum against L1 antigen /12/. Affinity-purified swine anti-rabbit IgG (DAKO) conjugated with rhodamine (1:75 dilution) was used as the second antibody.

\section{RESULTS AND DISCUSSION}

As observed in a previous study /11/, L1 immunoreactivity in the striatum was demonstrated by a uniform staining of the striatal neuropil (not shown). To quantify any possible change in L1 expression, we measured the mean staining intensity on both the lesioned and non-lesioned sides, as described in $/ 11 /$, using the Macintosh II $\times$-based image analysis program (Image 1.43, developed by W. Rasband, NIMH, Bethesda, MD). For the purpose of our study, we arbitrarily divided the striatum into five parts: the medial-periventricular
(M) part and the dorsomedial (DM), dorsolateral (DL), ventrolateral (VL), and ventromedial (VM) quadrants /11/. The medial-periventricular (M) region was defined as the area immediately adjacent to the ventricle containing no myelinated fiber bundles. For each location, staining intensity on the lesioned side was compared with that on the nonlesioned side (see Fig. 1).

Short-Term, Non-Rotators
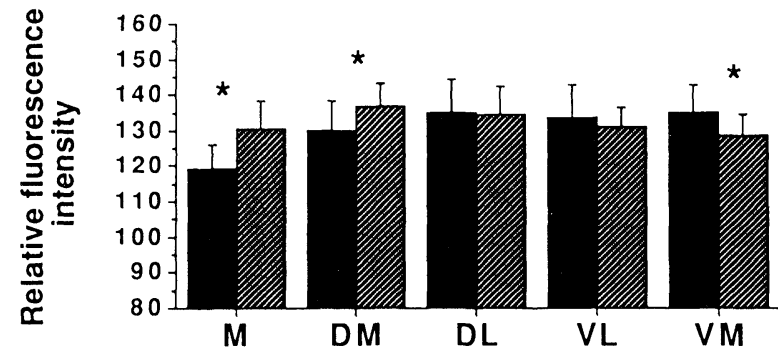

Short-Term, Rotators

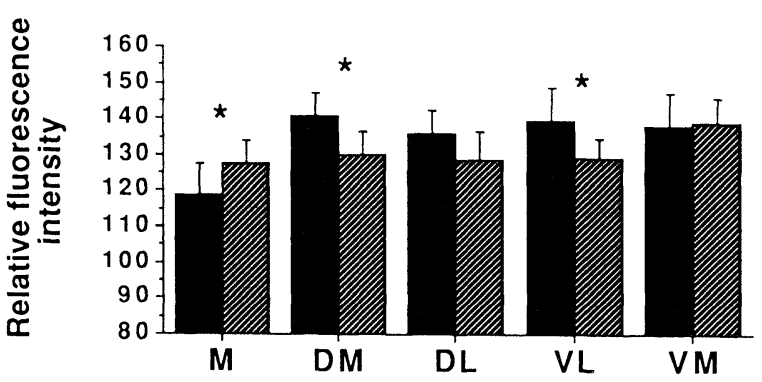

Long-Term, Rotators

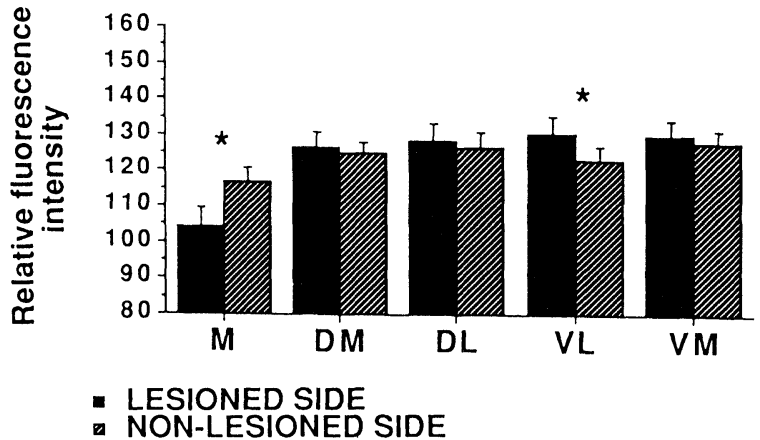

Fig. 1: Quantitative analysis of the intensity of L1 antigen immunofluorescence in the striatum of three groups. the second antibody was affinity-purified swine anti-rabbit IgG (DAKO) conjugated with rhodamine (1:75 dil).

$*=$ statistically significant 
Figure 1 shows that after 10 days (short-term), the side with partial SN lesions (non-rotators) showed decreased L1 antigen expression in the medial-periventricular and dorso-medial regions, with an increase in the ventro-medial striatum, when compared with the non-lesioned side. Complete SN lesions produced decreased $\mathrm{Ll}$ antigen expression in the medial-periventricular part of the striatum but increased $\mathrm{L} 1$ antigen expression in the dorso-medial and ventro-lateral parts of the striatum. After 3 months (long-term), complete SN lesions decreased L1 antigen expression in the medial-periventricular part of the striatum while increasing $\mathrm{L} 1$ antigen expression in the ventro-lateral parts of the striatum.

For the short-term rotators, a two-way ANOVA showed a statistically significant side $\mathrm{x}$-region interaction $[F(4,24)=4.2, p<0.01]$. Means contrasts demonstrated significantly decreased L1 immunostaining in the $M$ region $(p<0.05)$ and enhanced staining in the DM $(p<0.02)$ and VL $(p<0.03)$ regions.

For the long-term rotators, a statistically significant side $\mathrm{x}$-region interaction was seen $[F(4,44)=6.8, \quad p<0.0002]$. Means contrasts demonstrated significantly decreased L1 immunostaining in the $M$ region $(p<0.0001)$ and enhanced staining in the VL region $(p<0.02)$.

The dopaminergic neurons of the SN project to the striatum in a regular pattern, so that the ventral tegmental areas project to the ventral striatum and the lateral parts of the $\mathrm{SN}$ send afferents to the lateral striatal regions $/ 8,18 /$. The $\mathrm{SN}$ as a whole, however, innervates the entire striatum, so that when all or most of the $\mathrm{SN}$ dopaminergic neurons are destroyed, the entire striatum is deafferentated. Therefore, it is interesting that deafferentation of the entire striatum altered $\mathrm{L} 1$ antigen expression only in specific striatal regions.

In all groups, dopaminergic deafferentation decreased the expression of $\mathrm{L} 1$ antigen in the medial-periventricular (M) part of the striatum. In other regions, the changes were smaller and different patterns were seen in each group. For the short-term animals with complete lesions, L1 antigen expression was increased in the dorsomedial and ventrolateral parts of the striatum on the lesioned side as compared with the non-lesioned side. Some disturbances, particularly the increased
$\mathrm{Ll}$ expression within the ventrolateral areas of the striatum, persisted in the long-term animals.

The partial overlap between the areas of dopaminergic deafferentation and areas of altered $\mathrm{L} 1$ antigen expression in the striatum suggests that $\mathrm{L} 1$ antigen expression in the striatum is influenced not only by direct deafferentation but also by other factors. This notion is supported by our previous data indicating that cortical lesions, while deafferentating dorsal and dorso-lateral parts of striatum, induce changes only in the dorso medial region $/ 11$. Whether the activation of other circuitry or secretion of unidentified trophic factors is responsible for such changes is unclear, however.

Our results suggest that, in response to complete SN destruction, the deafferentated striatum transiently increases the synthesis of $\mathrm{L} 1$ antigen, primarily in the dorsal and ventrolateral areas. As the $\mathrm{L} 1$ antigen has a positive influence on neurite outgrowth, changes in L1 expression suggest the possibility of a molecular basis for plasticity in catecholamine-containing systems and may be related to plastic changes that might occur after injury. It is also possible that a similar increase in L1 antigen synthesis might be present in MPTPinduced or idiopathic Parkinsonism in humans and may encourage regeneration of dopaminergic terminals within the striatum after neuronal or adrenal tissue transplantation $/ 2,3,4 /$.

Recent data suggested that $\mathrm{SN}$ lesions in neonatal mice do not induce the expression of $\mathrm{Ll}$ antigen in the striatum $/ 7 /$. In that model, the completeness of the $\mathrm{SN}$ lesions did not seem to be confirmed by either behavioral tests or histologic examination. By contrast, our results indicate that complete and partial lesions of the SN show different patterns of $\mathrm{L} 1$ immunostaining. Moreover, the present study revealed that the region in which a consistent effect occurred in all groups corresponded to only a relatively small area that is located adjacent to the lateral ventricle. This difference demonstrates that the interaction between $\mathrm{L} 1$ antigen synthesis and striatal afferentation is complex and may explain, to some extent, the apparent inconsistency between the results of the two studies

Thus, it seems that the medial-periventricular part of the striatum is especially sensitive to alternations in $\mathrm{L} 1$ antigen synthesis because in all 
three groups of animals, lesions of the SN produced a decrease in $\mathrm{L} 1$ expression in this area. In addition, frontal cortex lesions have been shown to induce an increase in $\mathrm{L} 1$ antigen expression within the medialperiventricular region of the striatum /11/. Previous data and the results of the present study suggest a differential response of the medial-periventricular area of the striatum, depending upon which striatal afferents are removed or activated or both.

\section{ACKNOWLEDGMENTS}

We are grateful to $\mathrm{H}$. Eleanor Cannon-Spoor for editing the manuscript; to Melitta Schachner and Berd Gehring for their kind gift of antibodies; and to Wayne Rasband for providing and assisting with the use of the image-analysis system.

\section{REFERENCES}

1. Freed WJ. Functional brain tissue transplantation: Reversal of lesion-induced rotation by intraventricular substantia nigra and adrenal medulla grafts, with a note on intracranial retinal grafts. Biol Psychiat 1983; 18: 1205-1267.

2. Freed WJ, Cannon-Spoor HE. Cortical lesions interfere with behavioral recovery from unilateral substantia nigra lesions induced by brain grafts. Behav Brain Res 1989; 32: 279-288.

3. Freed WJ, Cannon-Spoor HE. Cortical lesions increase reinnervation of the dorsal striatum by substantia nigra grafts. Brain Res 1988; 46: 133-143.

4. Hallman H, Lange J, Olson L, Stromberg I, Jonsson G. Neurochemical and histochemical characterization of neurotoxic effects of 1-methyl-4-phenyl-1,2,3,6tetrahydropyridine on brain catecholamine neurons in the mouse. J Neurochem 1985; 44: 117-127.

5. Lagenaur C, Lemmon V. An L1-like molecule, the 8D9 antigen, is a potent substrate for neurite extension. Proc Natl Acad Sci USA 1987; 84: 77537757.

6. Lindner J, Rathjen F, Schachner M. L1 mono- and polyclonal antibodies modify cell migration in early postnatal mouse cerebellum. Nature $1983 ; 305$ : 427430.

7. O'Brien TF, Faissner A, Schachner M, Steindler DA. Afferent-boundary interactions in the developing neostriatal mosaic. Dev Brain Res 1992; 65 259-267.

8. Parent A, Mackey A, DeBellefeuille L. The subcortical afferents to cadate nucleus and putamen in the primate: A fluorescence retrograde double-labeling study. Neuroscience 1983; 10 1137-1150.

9. Poltorak M, Shimoda K, Freed WJ. L1 substrate enhances outgrowth of tyrosine-hydroxylase immunoreactive neurites in mesencephalic cell culture. Exp Neurol 1992; 117: 176-184.

10. Poltorak M, Williams JR, Freed WJ. Degradation fragments of $\mathrm{L} 1$ antigen enhance tyrosine-hydroxylase immunoreactive neurite outgrowth in mesencephalic cell culture.

11. Poltorak M, Herranz AS, Williams JR, Lauretti L, Freed WJ. Effects of frontal cortical lesions on mouse striatum: Reorganization of the cell recognition molecule, glial fiber, and synaptic protein expression in the dorso-medial striatum. J Neurosci 1993; 13 2217-2229.

12. Rathjen FG, Schachner M. Immunocytological and biochemical characterization of a new neuronal cellsurface component ( $\mathrm{L} 1$ antigen) which is involved in cell adhesion. EMBO J 1984; 3 1-10.

13. Schachner M. Immunohistochemistry and immunocytochemistry of neural cell types in vitro and in situ. In: Cuello A, ed. Immunohistochemistry, IBRO 1983; 399-429.

14. Schachner M. Cell-surface recognition and neuron-glia interactions. Ann NY Acad Sci 1991; 633 105-112.

15. Schachner M, Antonicek H, Fahring T, Faissner A, Fisher G, Kunemund V, et al. Families of neural cell adhesion molecules. In: Edelman GM, Cunningham BA, Thiery J-P, eds. Morphoregulatory molecules, New York: John Wiley \& Sons, Inc. 1990; 443-468.

16. Shults CW, Kimber TA. Mesencephalic dopaminergic cells exhibit increased density of neural cell adhesion molecule and polysialic acid during development. Dev Brain Res 1992; 65 161-172.

17. Stallcup WB, Beasley LL, Levine JM. Antibody against nerve growth factor inducible large external (NILE) glycoprotein labels nerve fiber tracts in the developing rat nervous system. J Neurosci 1985; 5: 1090-1101.

18. Szabo J. Organization of the ascending striatal afferents in monkeys. J Comp Neurol 1980; 189: 307. 

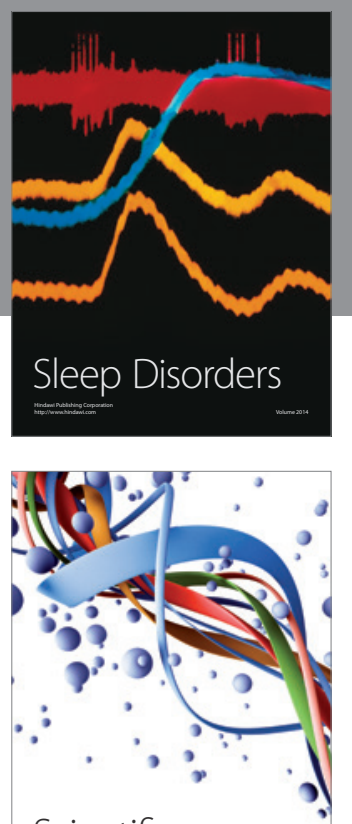

Scientifica
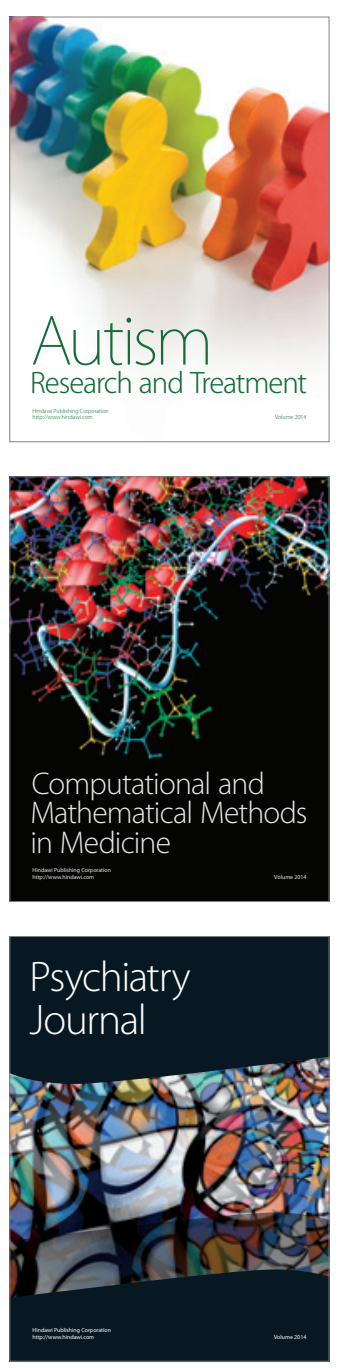
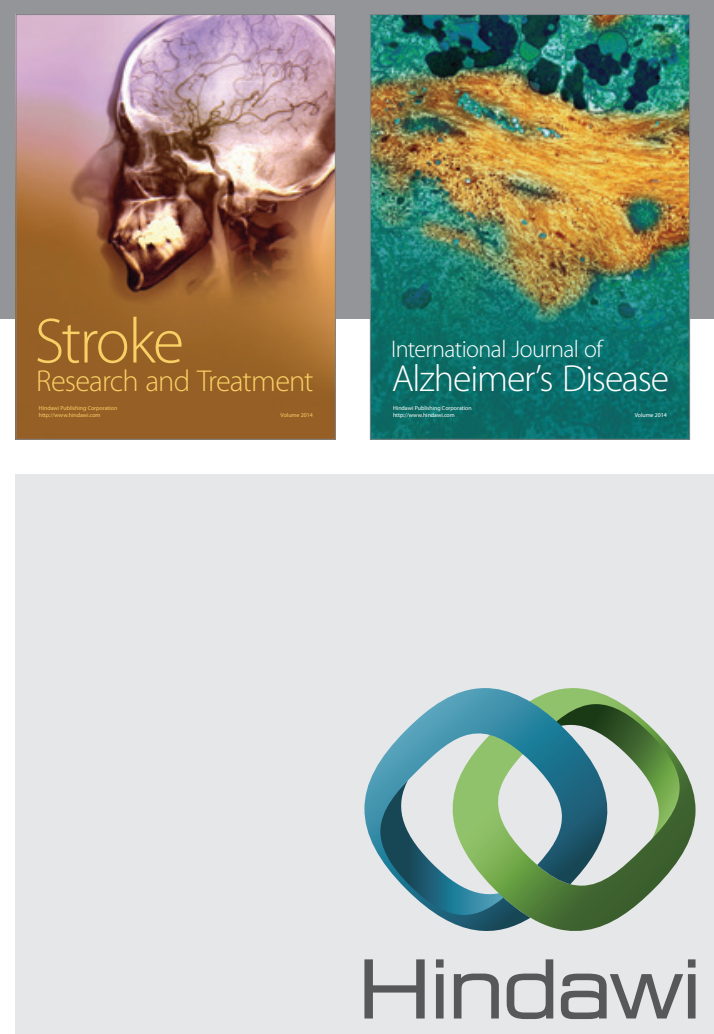

Submit your manuscripts at

http://www.hindawi.com
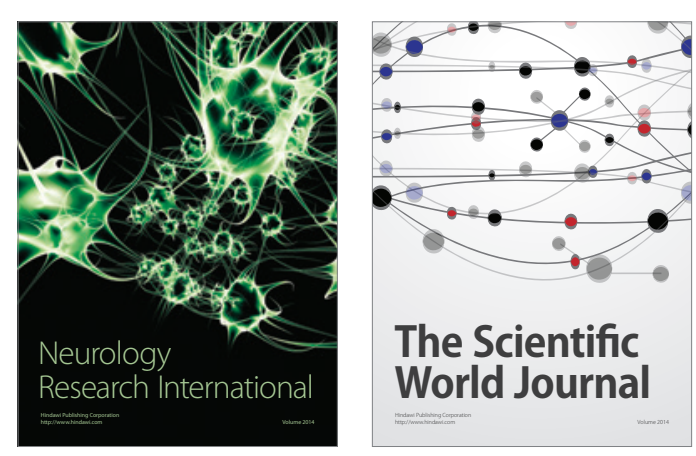

The Scientific World Journal

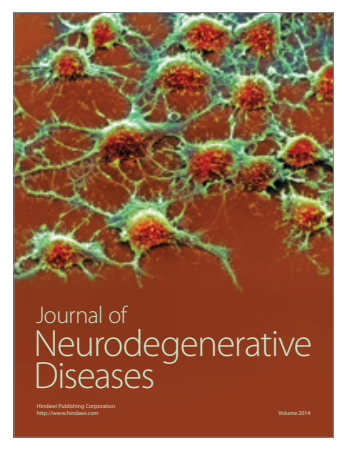

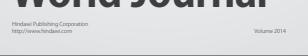

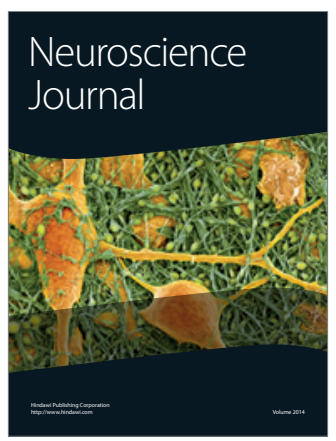

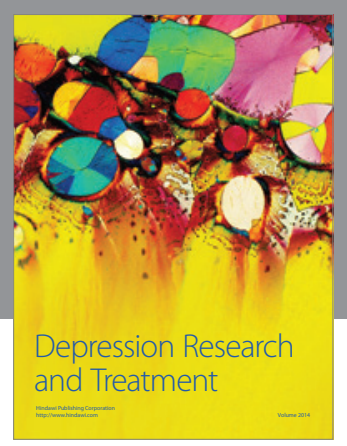
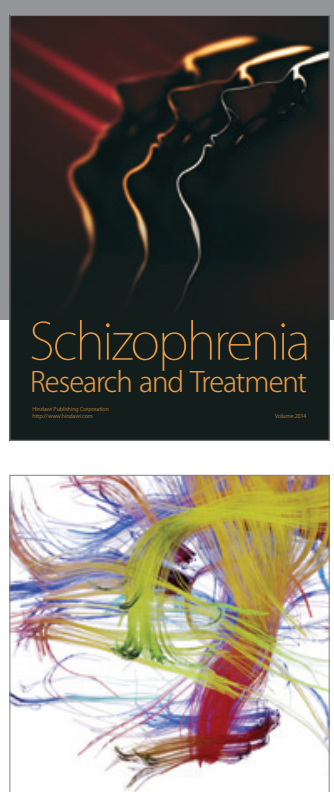

Brain Science

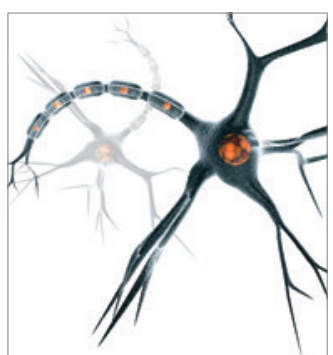

Neural Plasticity
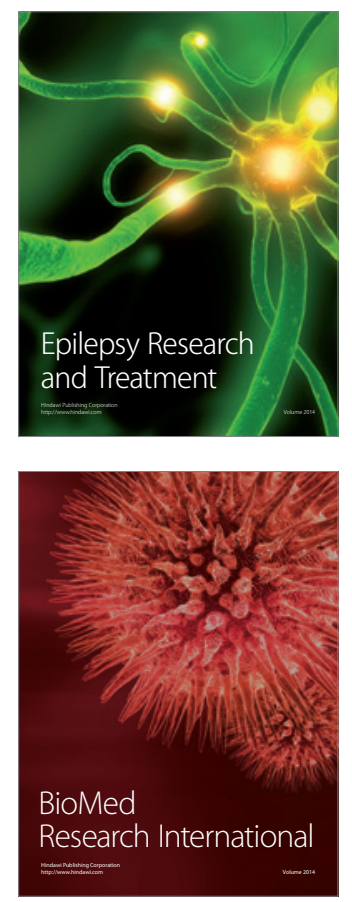

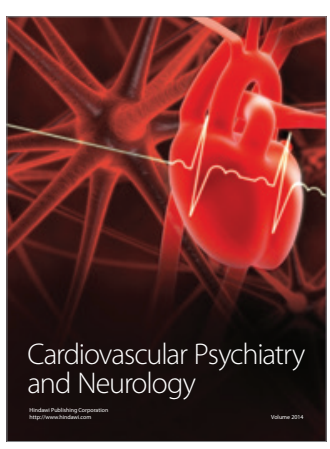

Parkinson's

Disease
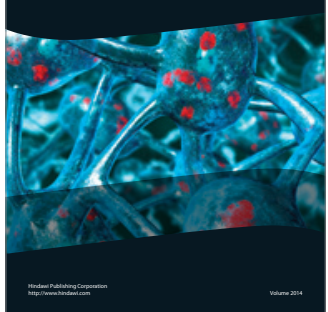